\title{
Acetaminophen attenuates glomerulosclerosis in obese Zucker rats via reactive oxygen species/p38MAPK signaling pathways
}

Cuifen Wang ${ }^{\mathrm{a}, \mathrm{b}, \mathrm{c}}$, Eric Blough ${ }^{\mathrm{a}, \mathrm{b}, *}$, Ravikumar Arvapallia ${ }^{\mathrm{a}, \mathrm{b}}$, Xiaoniu Dai ${ }^{\mathrm{c}}$, William E. Triest ${ }^{\mathrm{d}}$, John W. Leidy ${ }^{\mathrm{d}}$, Yanal Masannat ${ }^{\mathrm{e}}$, Miaozong $\mathrm{Wu}^{\mathrm{a}, \mathrm{b}, \mathrm{e}, *}$

${ }^{a}$ Center for Diagnostic Nanosystems, ${ }^{b}$ School of Pharmacy, and ${ }^{\mathrm{e}}$ Department of Internal Medicine, Joan C. Edwards School of Medicine, Marshall University, Huntington, WV 25755, USA

${ }^{\mathrm{c} S}$ Southeast University, Nanjing, Jiangsu, China

${ }^{\mathrm{d}}$ Huntington VA Medical Center, Huntington, WV 25704, USA

Received 7 May 2014; accepted 11 January 2015

*Corresponding author. Fax: (304) 696-3766.

E-mail address: wum@marshall.edu (M. Wu) or blough@marshall.edu (E. Blough).

${ }^{1}$ Abbreviations used: APAP, acetaminophen; DMSO, dimethyl sulfoxide; H\&E, hematoxylin and eosin; PAS, periodic acid-Schiff base; PSR, picro-sirius red; DHE, dihydroethidium; GAPDH, glyceraldehyde-3-phosphate dehydrogenase; TGF- $\beta$, transforming growth factor $\beta$; CTGF, connective tissue growth factor; MCP-1, monocyte chemoattractant protein; p38MAPK, p38 mitogen-activated protein kinase; 4-HNE, 4-hydroxynonenal; ROS, reactive oxygen species; ECM, extracellular matrix; HRMC, human renal mesangial cell; MCM, mesangial cell medium; FBS, fetal bovine serum; Nrf2, nuclear factor erythroid 2-related factor 2; GSH, glutathione; LC, lean control; OC, obese control; OV, obese vehicle; OT, obese treatment.

\footnotetext{
Abstract

Focal segmental glomerulosclerosis is a critical pathological lesion in metabolic syndrome-associated kidney disease that, if allowed to proceed unchecked, can lead to renal failure. However, the exact mechanisms underlying glomerulosclerosis remain unclear, and effective prevention strategies against glomerulosclerosis are currently limited. Herein, we demonstrate that chronic low-dose ingestion of acetaminophen ( $30 \mathrm{mg} / \mathrm{kg} / \mathrm{day}$ for $6 \mathrm{months})$ attenuates proteinuria, glomerulosclerosis, podocyte injury, and inflammation in the obese Zucker rat model of metabolic syndrome. Moreover, acetaminophen treatment attenuated renal fibrosis and the expression of profibrotic factors (fibronectin, connective tissue growth factor, transforming growth factor $\beta$ ), reduced inflammatory cell infiltration into the glomeruli, and decreased the expression of monocyte chemoattractant protein, glutathione (GSH) reductase, and nuclear factor erythroid 2-related factor 2, but increased the level of GSH synthetase in obese animals. Further in vivo and in vitro studies using human renal mesangial cells exposed to high glucose or hydrogen peroxide suggested that the renoprotective effects of acetaminophen are characterized by diminished renal oxidative stress and p38MAPK hyperphosphorylation.
} 
Keywords: Acetaminophen; Glomerulosclerosis; Obese Zucker rat; Human renal mesangial cell; Oxidative stress; p38MAPK; Glutathione synthetase; Free radicals

Metabolic syndrome affects approximately $34 \%$ of U.S. adults and is characterized by abdominal obesity, hyperglycemia, dyslipidemia, and hypertension [1,2]. In addition to the widely known effects that metabolic syndrome may have on the cardiovascular system, it is also a risk factor for the development of focal segmental glomerulosclerosis, which can lead to chronic kidney disease and renal failure if not properly managed $[1,3]$.

Glomerulosclerosis is characterized by the replacement of glomerular tissue by extracellular matrix $(\mathrm{ECM})^{1}$ proteins [4-6]. The pathogenesis of the metabolic syndrome-induced glomerulosclerosis is not fully understood; however, it is thought that elevations in tissue reactive oxygen species (ROS) levels may be one of the primary driving forces responsible for the development of fibrosis and the increased expression of transforming growth factor $\beta$ (TGF- $\beta$ ), connective tissue growth factor (CTGF), and monocyte chemoattractant protein (MCP-1) seen with this condition $[7,8]$. Whether diminishing renal ROS levels are associated with decreased glomerulosclerosis in metabolic syndrome is currently unclear.

Acetaminophen ( $N$-acetyl- $p$-aminophenol; APAP) is a widely used analgesic and antipyretic drug that exhibits antioxidant activity [9-17]. Whether acetaminophen is effective in the prevention of metabolic syndromeassociated glomerulosclerosis has, to our knowledge, not been examined. Using the obese Zucker rat model of metabolic syndrome, our data suggest that chronic low-dose acetaminophen ingestion ( $30 \mathrm{mg} / \mathrm{kg} / \mathrm{day})$ is associated with diminished proteinuria, decreased evidence of glomerulosclerosis, and reduced glomerular infiltration of inflammatory cells. Additional in vivo and cell culture studies using human renal mesangial cells (HRMCs) exposed to high glucose or $\mathrm{H}_{2} \mathrm{O}_{2}$ suggest that acetaminophen may induce these effects, at least in part, by attenuating cellular superoxide levels and p38 mitogen-activated protein kinase (p38MAPK) phosphorylation.

\section{$<$ H1 $>$ Materials and methods}

$<H 2>$ Materials

Acetaminophen, DMSO, D-glucose, D-mannitol, and CelLytic M cell lysis reagent were purchased from Sigma-Aldrich (St. Louis, MO, USA). Hydrogen peroxide was purchased from Acros Organics (Fair Lawn, NJ, USA). Hematoxylin and eosin (H\&E), periodic acid-Schiff base (PAS), and picro-sirius red (PSR) stain kits were obtained from Poly Scientific R\&D Corp. (Bay Shore, NY, USA). Dihydroethidium (DHE; No. D23107) was from Molecular Probes (Eugene, OR, USA). Primary antibodies against p38MAPK (No. 9212), phospho-p38MAPK (No. 4631), and GAPDH (No. 2118) were from Cell Signaling Technology (Danvers, MA, USA). Antibodies against ED1 (ab31630), CD5 (ab22356), TGF- $\beta$ (ab66043), CTGF (ab6992), MCP-1 (ab7202), 4-hydroxynonenal (4-HNE; ab46545), fibronectin (ab23750), desmin (ab15200), GSH reductase (ab16801), and GSH synthetase (ab124811) were obtained from Abcam (Cambridge, MA, USA). Nrf2 antibody (sc-722) was from Santa Cruz Biotechnology (Dallas, TX, USA). Pierce 660-nm protein assay reagent was from Fisher Scientific (Rockford, IL, USA). Creatinine colorimetric assay kit was obtained from Cayman Chemical (Ann Arbor, MI, USA). Human TGF- $\beta$ and CTGF ELISA kits were from TSZELISA (Waltham, MA, USA). Human MCP-1 ELISA kit was from BD Bioscience (San Jose, CA, USA). Human fibronectin ELISA kit was from Millipore (Billerica, MA, USA). Formaldehyde was from 
Polyscience (Warrington, PA, USA). HRMCs, mesangial cell medium (MCM), and fetal bovine serum (FBS) were purchased from Sciencell Research Laboratory (Carlsbad, CA, USA). Other chemicals used in this study were purchased from Sigma-Aldrich.

$<H 2>$ Animal study

Young male lean and obese Zucker rats were purchased from the Charles River Laboratories (Wilmington, MA, USA). The body weight of lean and obese animals at 4 weeks of age was $100.4 \pm 6.6$ and $116.7 \pm 9.9 \mathrm{~g}$, respectively $(P \leq 0.05)$. Obese Zucker rats were randomly assigned into one of three groups $(n=6$ each): obese control (OC), obese vehicle (OV; $0.08 \mu 1 \mathrm{DMSO} / \mathrm{kg} /$ day), or obese treated with acetaminophen (OT; APAP was predissolved in DMSO and given at $30 \mathrm{mg} / \mathrm{kg} /$ day via drinking water for 26 weeks). Age-matched lean Zucker rats were used as controls ( $\mathrm{LC} ; n=6$ ). At 30 weeks of age, the rats were anesthetized, and urine and kidneys were collected as described previously [17].

\section{$<H 2>$ Urinary protein measurement}

Total protein in urine was measured using the Pierce $660-\mathrm{nm}$ protein assay reagent. Urine creatinine was determined by colorimetric assay as described previously [17]. Urine protein excretion was expressed as milligrams protein per milligram creatinine for each animal.

$<H 2>$ Histological assessment of the kidney

Renal sections ( $8 \mu \mathrm{m})$ were stained with H\&E, PAS, and PSR. The severity of glomerulosclerosis was evaluated by determining the number of glomeruli showing sclerosis and the area showing sclerosis within the glomerulus [18]. Briefly, the severity of sclerosis for each glomerulus was graded from 0 to 4: grade 0 , normal; grade $1,<25 \%$; grade $2,25-50 \%$; grade $3,50-75 \%$; and grade $4,>75 \%$ of the glomerular tuft. A glomerulosclerosis score for each animal was calculated as follows: $[(1 \times$ the number of glomeruli with score 1$)+(2 \times$ the number of glomeruli with score 2$)+(3 \times$ the number of glomeruli with score 3$)+(4 \times$ the number of glomeruli with score $4)] /$ total number of glomeruli examined.

\section{$<H 2>$ Immunofluorescence and staining for superoxide}

Immunofluorescence was performed for the assessment of CD5, ED1, TGF- $\beta$, CTGF, MCP-1, 4-HNE, and desmin, and the fluorescent dye DHE was used to measure the superoxide anion production as previously described

[17]. The inflammatory cells or the biomarker expression was quantified using ImageJ software and expressed as the number of positive cells or mean fluorescence intensity per glomerular cross section. At least 50 glomeruli per animal were evaluated at $400 \times$ magnification. Tissue staining and analysis were done in a blinded fashion.

\section{$<H 2>$ Immunoblotting}

The measurement of desmin, fibronectin, MCP-1, p-p38MAPK, p38MAPK, GSH synthetase, GSH reductase, and Nrf2 protein levels was determined using immunoblotting as described previously [19].

\section{$<H 2>$ Cell culture, treatment, ELISA, and Western blot analysis}

HRMCs were cultured in MCM supplemented with $2 \%$ FBS. After quiescence was attained with serum-free MCM for $24 \mathrm{~h}$, the cells were incubated in MCM containing $5.5 \mathrm{mM}$ glucose (CON), $25 \mathrm{mM}$ glucose (HG), $25 \mathrm{mM}$ glucose with acetaminophen (APAP 3 or $10 \mu \mathrm{M}$ ) or 0.1\% DMSO (DMSO), or $5.5 \mathrm{mM}$ glucose with $19.5 \mathrm{mM}$ mannitol. In other experiments, cells were exposed to $10 \mu \mathrm{M} \mathrm{H}_{2} \mathrm{O}_{2}$. At the end of treatments, the medium was 
collected by centrifugation at $1000 \mathrm{~g}$ for $10 \mathrm{~min}$ to remove cells, and the supernatant was assayed in triplicate for secreted fibronectin, TGF- $\beta$, CTGF, and MCP-1 using ELISA kits according to the manufacturer's protocols. Cells were collected by centrifugation and lysed in CelLytic M cell lysis reagent for further p-p38MAPK and p38MAPK analysis by Western blot [20].

$<H 2>$ HRMC immunofluorescence and staining for superoxide

HRMCs were cultured on coverslips in a 12-well plate for $24 \mathrm{~h}$ and then made quiescent for $24 \mathrm{~h}$. After the treatment for 48 as indicated, immunofluorescence staining for fibronectin and 4-HNE was performed as described above, whereas intracellular superoxide levels were assessed by staining with DHE. The mean fluorescence intensity per nucleus (for DHE staining) or per cell (for 4-HNE staining) was quantified using ImageJ software. At least 100 nuclei or cells per sample were evaluated at $400 \times$ magnification. Cell staining and analysis were done in a blinded fashion.

\section{$<H 2>$ Statistical analysis}

Data are presented as the mean \pm standard error. Multiple comparisons were performed using a one-way ANOVA and the Tukey post hoc test as appropriate. A $P \leq 0.05$ was considered statistically significant.

\section{$<$ H1 $>$ Results}

$<H 2>$ Acetaminophen reduces proteinuria and podocyte damage in obese Zucker rats

The ratio of total protein/creatinine in urine was measured to investigate the protective effect of acetaminophen on glomerular function. The 30 -week-old OC and OV rats had higher urinary protein excretion than age-matched lean controls (Fig. 1A; $P \leq 0.05$ ), whereas chronic acetaminophen treatment significantly attenuated proteinuria in the obese rats $(P \leq 0.05)$.

Podocytes constitute the main component of the glomerular filtration barrier and provide a defense against urinary protein loss. Therefore, podocyte injury plays an important role in the initiation and progression of proteinuria $[21,22]$. To investigate whether obesity-associated proteinuria and the protective effect of acetaminophen were related to the integrity of podocytes, the expression of desmin, a biomarker of podocyte injury [23], was evaluated spatially and quantitatively using immunofluorescence and immunoblotting, respectively. As shown in Fig. 1B, intraglomerular desmin expression was higher in both obese control and vehicle rats than in the lean control rats, whereas it was significantly reduced in the acetaminophen-treated obese rats $(P \leq 0.05)$. The alteration of desmin expression was further validated by immunoblotting (Fig. 1C).

$<H 2>$ Acetaminophen alleviates the severity of glomerulosclerosis in the obese Zucker rat

The irregular glomerulus and expansion of Bowman's capsule was observed in H\&E-stained tissue sections from obese control and vehicle rats (Fig. 2A). Treatment with acetaminophen effectively restored the normal glomerulus morphology in the obese rats (Fig. 2A). Glycogen deposition in the glomeruli was measured by PAS staining and scored to indicate the severity of glomerulosclerosis. Focal glomerulosclerosis was observed in the obese control and vehicle rats, but diminished with acetaminophen treatment ( $P \leq 0.05$; Figs. 2A and 2B). PSR staining demonstrated that collagen accumulation was enhanced in the glomeruli or in the periglomerular area of obese control and vehicle rats and reduced with acetaminophen treatment (Fig. 2A).

$<H 2>$ Acetaminophen reduces inflammatory cell infiltration and MCP-1 expression in glomeruli 
Intraglomerular macrophages (ED1-positive cells) and lymphocytes (CD5-positive cells) were markedly increased in obese control and vehicle animals compared with the lean controls $(\mathrm{P} \leq 0.05)$, but reduced with chronic acetaminophen treatment $(P \leq 0.05$; Figs. $3 \mathrm{~A}$ and $3 \mathrm{~B})$. To further confirm the effect of acetaminophen on the attenuation of inflammation, the MCP-1 expression was evaluated using immunofluorescence and immunoblotting, respectively. Intraglomerular MCP-1 expression was also significantly upregulated in obese control and vehicle animals compared with the lean controls $(P \leq 0.05)$, but decreased in the acetaminophen-treated obese animals $(P \leq$ 0.05; Fig. 3C). A similar alteration in MCP-1 expression was seen in kidney total protein lysate when detected by immunoblotting (Fig. 3D).

$<H 2>$ Acetaminophen decreases the expression of profibrotic factors in kidneys

Glomerulosclerosis results from the accumulation of excess ECM protein and causes glomerular scarring [24]. The expression of fibronectin, a major component of the ECM [25], was examined by immunoblotting. The amount of fibronectin was increased in both obese control and vehicle rats compared with the lean rats $(P \leq 0.05)$, but reduced by acetaminophen treatment $(P \leq 0.05$; Fig. 4A). TGF- $\beta$ and CTGF immunoreactivity was significantly increased in obese control and vehicle animals $(P \leq 0.05)$, but decreased after acetaminophen treatment $(P \leq 0.05$; Figs. 4B and 4C).

$<$ H2>Acetaminophen attenuates high-glucose-induced extracellular fibronectin deposition, profibrotic factors, and MCP-1 secretion in HRMCs

Although many glomerular cell types contribute to glomerulosclerosis, recent data have suggested that the mesangial cells are the major source of the scar tissue formation observed during glomerulosclerosis [26]. Among metabolic disorders in patients with metabolic syndrome, hyperglycemia is considered to be one of the greatest risks for glomerulosclerosis [27]. Our in vivo experiment demonstrated that acetaminophen treatment did not alter the increased blood glucose seen in obese animals (data not shown), suggesting that the protective effects of acetaminophen are probably mediated by its ability to attenuate the deteriorative effects of hyperglycemia on the development of glomerulosclerosis. To further investigate the possibility and the potential mechanism(s), HRMCs were cultured in the presence of elevated glucose levels. Consistent with our in vivo data, high glucose, but not mannitol (as the osmotic control), increased extracellular deposition of fibronectin (insoluble form, Fig. 5A) and the amount of fibronectin in the medium (soluble form, Fig. 5B). Importantly, acetaminophen was able to reverse highglucose-induced increases in extracellular deposition of fibronectin $(P \leq 0.05$; Fig. 5A) and the secretion of fibronectin, TGF- $\beta$, CTGF, and MCP-1 into the medium (Figs. 5B-5E).

$<H 2>$ Acetaminophen diminishes ROS generation in glomeruli and HRMCs exposed to high glucose

To investigate whether the attenuation of oxidative stress is involved in mediating the protective effect of acetaminophen on glomerulosclerosis, superoxide generation and lipid peroxidation in glomeruli from obese animals and in vitro high-glucose-treated HRMCs were evaluated. The fluorescence intensity of DHE in glomeruli was increased by 1.45- and 1.5-fold in obese control and vehicle animals, respectively, compared with that in lean control animals (Fig. 6A). This increase was significantly attenuated by chronic acetaminophen treatment $(P \leq 0.05$; Fig. 6A). 4-HNE, a ROS-derived oxidative product, was used as a second marker of oxidative stress. The level of 4HNE protein adducts in glomeruli was significantly increased in obese animals, but diminished with acetaminophen 
treatment (Fig. 6B). Similar findings were observed in the cultured HRMCs when exposed to high glucose but attenuated by acetaminophen (Figs. 6C and 6D).

$<H 2>$ Acetaminophen inhibits p38MAPK hyperactivation in obese kidneys and HRMCs exposed to high glucose

In several disease models, the p38MAPK pathway has been shown to play critical roles in response to stress stimulation and mediating cellular and tissue remodeling [13,28-30]. Compared to the lean control animals, renal p38MAPK phosphorylation (p-p38MAPK) and the p-p38MAPK/p38MAPK ratio were increased in both obese control and vehicle animals $(P \leq 0.05)$ but diminished with chronic acetaminophen treatment $(P \leq 0.05 ;$ Fig. 7A $)$. Similar findings were observed in in vitro cultured HRMCs exposed to high glucose (HG vs CON, $P \leq 0.05$ ) in the absence or presence of acetaminophen $(10 \mu \mathrm{M})$ for $48 \mathrm{~h}$ (APAP vs HG, $P \leq 0.05$; Fig. 7B).

$<H 2>$ Acetaminophen reduces $\mathrm{H}_{2} \mathrm{O}_{2}$-induced $p 38 M A P K$ activation and TGF- $\beta$ and MCP-1 secretion

To further confirm the inhibition of acetaminophen on oxidative stress and the p38MAPK signaling pathway, we treated HRMCs with $\mathrm{H}_{2} \mathrm{O}_{2}$ and investigated p38MAPK activation, along with the secretion of TGF- $\beta$ and MCP- 1 . Compared to controls, exposure to $\mathrm{H}_{2} \mathrm{O}_{2}(12 \mathrm{~h})$ elevated the expression of p-p38MAPK, the ratio of $\mathrm{p}$ p38MAPK/p38MAPK, and the secretion of TGF- $\beta$ and MCP-1 into the medium (Figs. $8 \mathrm{~A}-8 \mathrm{C}$ ). Importantly, acetaminophen treatment significantly diminished $\mathrm{H}_{2} \mathrm{O}_{2}$-induced increases in the p-p38MAP levels and the secretion of TGF- $\beta$ and MCP-1 into the medium (Figs. $8 \mathrm{~A}-8 \mathrm{C}$ ).

$<H 2>$ Acetaminophen increases GSH synthetase expression and alleviates GSH reductase and Nrf2 expression in obese kidney

To further understand the molecular mechanism of acetaminophen in attenuation of renal oxidative stress, renal GSH synthetase and reductase and Nrf2 in kidney protein lysate were measured by immunoblotting. Compared to the lean control animals, renal GSH synthetase was downregulated in both obese control and vehicle animals $(P \leq$ 0.05 ) but increased after chronic acetaminophen treatment ( $P \leq 0.05$; Fig. 9A). Renal GSH reductase and Nrf2 protein levels were elevated in obese control and vehicle animals $(P \leq 0.05)$ but decreased after acetaminophen treatment $(P \leq 0.05$; Figs. 9B and 9C).

\section{$<$ H1 $>$ Discussion}

It is thought that focal segmental glomerulosclerosis is a critical pathological lesion in metabolic syndrome [31]. Using the obese Zucker rat model of metabolic syndrome, which exhibits focal segmental glomerulosclerosis and proteinuria [4-6], we demonstrate for the first time the potential inhibitory effects of acetaminophen on proteinuria, fibrosis, inflammation, and glomerulosclerosis seen in metabolic syndrome. Our data also suggest that these beneficial effects may be related to the ability of acetaminophen to reduce cellular oxidative stress, the activation p38MAPK, and the upregulation of fibronectin, TGF- $\beta$, CTGF, and MCP-1.

Glomerulosclerosis is associated with the replacement of glomerular tissue by ECM proteins, leading to the loss of glomerulus function. We observed that renal expression of fibronectin, a major ECM protein, was increased in obese Zucker rats and, importantly, decreased after acetaminophen treatment (Fig. 4A). It has been shown that hyperglycemia can induce mesangial activation and the pathogenesis of glomerulosclerosis [27]. Although we and others have previously reported that acetaminophen is able to reduce blood glucose levels in aging and streptozotocin-induced diabetes animal models $[10,13]$, we did not observe a similar finding in the present study. 
These data suggest that the protective effects of acetaminophen on glomerulosclerosis are probably not due to its ability to change blood glucose levels but, rather, somehow instead related to its ability to attenuate the damaging effects of hyperglycemia.

It is thought that damaging effects of hyperglycemia are mediated, at least in part, by the production of ROS $[32,33]$. In the present study, we observed significant increases in ROS level and lipid peroxidation in the glomeruli from obese Zucker control and vehicle rats and in the cultured HRMCs treated with higher glucose, whereas they were reduced with acetaminophen treatment (Figs. 6A-6D). These data are consistent with our previous findings that showed diminished oxidation of macromolecules (protein, lipid, and DNA) in the tubulointerstitium after acetaminophen intervention [17], supporting the protective role of acetaminophen in reducing renal oxidative stress seen with metabolic syndrome. To understand the underpinning molecular mechanisms, we have studied whether acetaminophen can reduce renal ROS production [17]. Our data suggest that acetaminophen treatment can inhibit renal NADPH oxidase (Nox2 and Nox4) expression [17], an important source of ROS generation. To further investigate whether acetaminophen can also improve renal antioxidant capacity, here we measured the expression of renal glutathione synthetase and reductase. Consistent with other findings of antioxidant enzymes in metabolic syndrome models [34,35], we found that acetaminophen treatment was able to attenuate the alteration in renal GSH synthetase and reductase in the kidney from obese Zucker rats (Figs. 9A and 9B). Given the fact of reduced glutathione production and increased oxidative stress in obese Zucker kidney (Figs. 6 and 9), it is not surprising that the expression of $\mathrm{Nrf2}$, a critical transcription factor regulating glutamate-cysteine ligase expression [36], was increased in the kidney from both obese control and vehicle animals (Fig. 9C), which was expected to compensate for the impaired antioxidant capacity. These data together supported that an increased antioxidant mechanism also contributes to the renoprotective effects of acetaminophen. Although not tested in the current study, other work has shown that the phenolic ring of acetaminophen also carries ROS-scavenging properties [10], which may also result in reducing the ROS content seen in glomeruli from obese rats and HRMCs exposed to high glucose (Fig. 6). It should be noted that the antioxidant properties of acetaminophen seen in the current study and others $[11,12,14,15,17]$ are dependent on its dosage, as a high and toxic dose of acetaminophen can actually induce nitric oxide production and oxidative stress [37,38].

Recent data have demonstrated that the activation of p38MAPK is particularly important in mediating the cell response to increased oxidative stress $[13,28-30]$ and that it may be involved in the pathogenesis of renal injury [28]. Other reports have demonstrated that p38MAPK phosphorylation is increased in cultured mesangial cells exposed to high glucose and in the glomeruli of various animal models exhibiting diabetic nephropathy, including the obese Zucker rat $[30,39]$. We previously reported that acetaminophen is able to attenuate p38MAPK hyperphosphorylation in aged skeletal muscle [13]. Consistent with these data, we noted significant increases in p38MAPK phosphorylation in the obese kidneys (OC and OV) and in HRMCs exposed to high glucose or $\mathrm{H}_{2} \mathrm{O}_{2}$ and, importantly, that these increases were reduced by acetaminophen treatment (Figs. 7 and 8). Among the downstream mediators of $\mathrm{p} 38 \mathrm{MAPK}$ signaling, it is thought that TGF- $\beta$ may play a critical role, as the inhibition of $\mathrm{p} 38 \mathrm{MAPK}$ in mesangial cells can block the upregulation of TGF- $\beta$ and fibronectin protein seen under conditions of increased glucose $[28,40,41]$. TGF- $\beta$ activity is increased in both human and experimental glomerulosclerosis, whereas the 
inhibition of TGF- $\beta$ signaling by the administration of an anti-TGF- $\beta$ antibody can attenuate the enhanced glomerular ECM expression seen in experimental glomerulosclerosis [42]. Consistent with our findings of reduced oxidative stress and p38MAPK activation by acetaminophen (Figs. 6-8), we also found that TGF- $\beta$ and fibronectin expression in the obese Zucker glomeruli (Fig. 4) and cultured HRMCs exposed to high glucose or $\mathrm{H}_{2} \mathrm{O}_{2}$ was diminished with acetaminophen treatment (Figs. 5A, 5B, 5C, and 8B).

The CTGF is thought to act as a downstream mediator of TGF- $\beta$ signaling in the regulation of ECM protein expression $[43,44]$. Recent studies have demonstrated that CTGF expression is strongly upregulated in diabetic glomerulosclerosis and cultured mesangial cells exposed to high glucose [45]. Consistent with our fibronectin, TGF$\beta$, and p38MAPK data (Figs. 4, 5, and 7), we found that chronic acetaminophen treatment also attenuated CTGF levels in the obese Zucker rat glomeruli and in HRMCs subjected to high glucose (Figs. 3C, 3D, and 5D). Taken together, these data suggest that the inhibitory effects of acetaminophen on fibronectin secretion might be mediated by reductions in $\mathrm{p} 38 \mathrm{MAPK} / \mathrm{TGF}-\beta / \mathrm{CTGF}$ signaling.

In addition to its role in controlling the expression of TGF- $\beta$, CTGF, and fibronectin, increased oxidative stress/p38MAPK activation is also likely to play a role in regulating the expression of MCP-1 expression and the inflammation process $[46,47]$. The MCP-1 is a chemokine produced by mesangial cells that is suggested to play an important role in recruiting macrophages into the glomeruli $[7,18,48,49]$. Moreover, inflammation also contributes to the pathogenesis of glomerulosclerosis, and anti-inflammatory agents have been reported able to prevent or retard the progression of glomerulosclerosis under high-glucose conditions [50]. Similar to that noted by others [7,47,49], our in vivo and in vitro studies suggest that MCP-1 expression is upregulated in the obese Zucker glomerulus and that its secretion from HRMCs is increased after exposure to elevated glucose or $\mathrm{H}_{2} \mathrm{O}_{2}$ levels, whereas these changes were significantly diminished by acetaminophen (Figs. 3C, 3D, 5E, and 8C). To investigate whether increased MCP-1 levels were associated with macrophage and lymphocyte infiltration, immunohistochemistry using antibodies against ED1 and CD5 was performed. Our data suggested that acetaminophen treatment was associated with decreased intraglomerular accumulation of macrophages and lymphocytes in the obese Zucker rat kidney (Figs. $3 \mathrm{~A}$ and $3 \mathrm{~B})$. These data are consistent with the notion that the inhibition $\mathrm{p} 38 \mathrm{MAPK} / \mathrm{MCP}-1 /$ inflammation may also play a role in mediating the renoprotective effects of acetaminophen.

In summary, this study provides the first evidence that acetaminophen at $30 \mathrm{mg} / \mathrm{kg} / \mathrm{day}$ may be useful for attenuating the development of the glomerulosclerosis seen in patients with metabolic syndrome. Specifically, our data suggest that acetaminophen treatment is associated with diminished glomeruli expression of profibrotic factors and decreased inflammation. These findings appear to be mediated, at least in part, by the ability of acetaminophen to diminish renal oxidative stress (decreased cellular ROS generation and improved antioxidant capacity) and inhibit p38MAPK activation (Fig. 10). Additional research to confirm the therapeutic efficacy of employing acetaminophen to slow glomerulosclerosis progression using other models and experimental designs may be warranted.

\section{Acknowledgments}

This work was supported by NASA EPSCoR NNX13AN08A (M.W.) and Department of Energy Grant DESC0005162 (E.B.). The authors acknowledge the support of the Huntington VA Medical Center and the Joan C. 
Edwards School of Medicine Training Program in Endocrinology for laboratory space and equipment.

\section{Authors' contributions}

M. Wu, C. Wang, and E. Blough participated in research design; C. Wang, M. Wu, R. Arvapalli, W.E. Triest, J.W. Leidy, and Y. Masannat conducted experiments and data collection; C. Wang and X. Dai performed data analysis and prepared figures; and C. Wang, M. Wu, and E. Blough wrote or contributed to the writing of the manuscript.

\section{References}

[1] Thomas, G.; Sehgal, A. R.; Kashyap, S. R.; Srinivas, T. R.; Kirwan, J. P.; Navaneethan, S. D. Metabolic syndrome and kidney disease: a systematic review and meta-analysis. Clin. J. Am. Soc. Nephrol. 6:2364-2373; 2011.

[2] Ervin, R. B. Prevalence of metabolic syndrome among adults 20 years of age and over, by sex, age, race and ethnicity, and body mass index: United States, 2003-2006. Natl. Health Stat. Rep. (13):1-7; 2009.

[3] el Nahas, A. M.; Muchaneta-Kubara, E. C.; Essawy, M.; Soylemezoglu, O. Renal fibrosis: insights into pathogenesis and treatment. Int. J. Biochem. Cell Biol. 29:55-62; 1997.

[4] Rodriguez-Iturbe, B.; Quiroz, Y.; Shahkarami, A.; Li, Z.; Vaziri, N. D. Mycophenolate mofetil ameliorates nephropathy in the obese Zucker rat. Kidney Int. 68:1041-1047; 2005.

[5] Singh, A. K.; Kari, J. A. Metabolic syndrome and chronic kidney disease. Curr. Opin. Nephrol. Hypertens.

22:198-203; 2013.

[6] Aleixandre de Artinano, A.; Miguel Castro, M. Experimental rat models to study the metabolic syndrome. Br. J. Nutr. 102:1246-1253; 2009.

[7] Ha, H.; Yu, M. R.; Choi, Y. J.; Kitamura, M.; Lee, H. B. Role of high glucose-induced nuclear factor-kappaB activation in monocyte chemoattractant protein-1 expression by mesangial cells. J. Am. Soc. Nephrol. 13:894-902; 2002.

[8] Yamagishi, S.; Inagaki, Y.; Okamoto, T.; Amano, S.; Koga, K.; Takeuchi, M.; Makita, Z. Advanced glycation end product-induced apoptosis and overexpression of vascular endothelial growth factor and monocyte chemoattractant protein-1 in human-cultured mesangial cells. J. Biol. Chem. 277:20309-20315; 2002.

[9] Dinis, T. C.; Maderia, V. M.; Almeida, L. M. Action of phenolic derivatives (acetaminophen, salicylate, and 5aminosalicylate) as inhibitors of membrane lipid peroxidation and as peroxyl radical scavengers. Arch. Biochem.

Biophys. 315:161-169; 1994.

[10] Shertzer, H. G.; Schneider, S. N.; Kendig, E. L.; Clegg, D. J.; D'Alessio, D. A.; Genter, M. B. Acetaminophen normalizes glucose homeostasis in mouse models for diabetes. Biochem. Pharmacol. 75:1402-1410; 2008.

[11] Nam, T. G.; Nara, S. J.; Zagol-Ikapitte, I.; Cooper, T.; Valgimigli, L.; Oates, J. A.; Porter, N. A.; Boutaud, O.; Pratt, D. A. Pyridine and pyrimidine analogs of acetaminophen as inhibitors of lipid peroxidation and cyclooxygenase and lipoxygenase catalysis. Org. Biomol. Chem. 7:5103-5112; 2009.

[12] DuBois, R. N.; Hill, K. E.; Burk, R. F. Antioxidant effect of acetaminophen in rat liver. Biochem. Pharmacol. 32:2621-2622; 1983. 
[13] Wu, M.; Desai, D. H.; Kakarla, S. K.; Katta, A.; Paturi, S.; Gutta, A. K.; Rice, K. M.; Walker, E. M., Jr.; Blough, E. R. Acetaminophen prevents aging-associated hyperglycemia in aged rats: effect of aging-associated hyperactivation of p38-MAPK and ERK1/2. Diabetes Metab. Res. Rev. 25:279-286; 2009.

[14] Wu, M.; Katta, A.; Gadde, M. K.; Liu, H.; Kakarla, S. K.; Fannin, J.; Paturi, S.; Arvapalli, R. K.; Rice, K. M.; Wang, Y.; Blough, E. R. Aging-associated dysfunction of Akt/protein kinase B: S-nitrosylation and acetaminophen intervention. PLoS One 4:e6430; 2009.

[15] Shertzer, H. G.; Kendig, E. L.; Nasrallah, H. A.; Johansson, E.; Genter, M. B. Protection from olanzapineinduced metabolic toxicity in mice by acetaminophen and tetrahydroindenoindole. Int. J. Obes. (London) 34:970979; 2010.

[16] Blough, E. R.; Wu, M. Acetaminophen: beyond pain and fever-relieving. Front. Pharmacol. 2:72; 2011.

[17] Wang, C.; Blough, E. R.; Arvapalli, R.; Dai, X.; Paturi, S.; Manne, N.; Addagarla, H.; Triest, W. E.; Olajide, O.; $\mathrm{Wu}, \mathrm{M}$. Metabolic syndrome-induced tubulointerstitial injury: role of oxidative stress and preventive effects of acetaminophen. Free Radic. Biol. Med. 65:1417-1426; 2013.

[18] Li, Z.; Rodriguez-Iturbe, B.; Ni, Z.; Shahkarami, A.; Sepassi, L.; Vaziri, N. D. Effect of hereditary obesity on renal expressions of NO synthase, caveolin-1, Akt, guanylate cyclase, and calmodulin. Kidney Int. 68:2766-2772; 2005 .

[19] Wang, C.; Wu, M.; Arvapalli, R.; Dai, X.; Mahmood, M.; Driscoll, H.; Rice, K. M.; Blough, E. Acetaminophen attenuates obesity-related renal injury through ER-mediated stress mechanisms. Cell. Physiol. Biochem. 33:11391148; 2014.

[20] Wang, C.; Jiang, Z.; Yao, J.; Wu, X.; Sun, L.; Liu, C.; Duan, W.; Yan, M.; Liu, J.; Zhang, L. Participation of cathepsin B in emodin-induced apoptosis in HK-2 cells. Toxicol. Lett. 181:196-204; 2008.

[21] Meyer, T. W.; Bennett, P. H.; Nelson, R. G. Podocyte number predicts long-term urinary albumin excretion in Pima Indians with type II diabetes and microalbuminuria. Diabetologia 42:1341-1344; 1999.

[22] Wharram, B. L.; Goyal, M.; Wiggins, J. E.; Sanden, S. K.; Hussain, S.; Filipiak, W. E.; Saunders, T. L.; Dysko, R. C.; Kohno, K.; Holzman, L. B.; Wiggins, R. C. Podocyte depletion causes glomerulosclerosis: diphtheria toxininduced podocyte depletion in rats expressing human diphtheria toxin receptor transgene. J. Am. Soc. Nephrol. 16:2941-2952; 2005.

[23] Chen, Z. H.; Qin, W. S.; Zeng, C. H.; Zheng, C. X.; Hong, Y. M.; Lu, Y. Z.; Li, L. S.; Liu, Z. H. Triptolide reduces proteinuria in experimental membranous nephropathy and protects against C5b-9-induced podocyte injury in vitro. Kidney Int. 77:974-988; 2010.

[24] Pozzi, A.; Voziyan, P. A.; Hudson, B. G.; Zent, R. Regulation of matrix synthesis, remodeling and accumulation in glomerulosclerosis. Curr. Pharm. Des. 15:1318-1333; 2009.

[25] Singh, P.; Carraher, C.; Schwarzbauer, J. E. Assembly of fibronectin extracellular matrix. Annu. Rev. Cell Dev. Biol. 26:397-419; 2010.

[26] Zheng, H.; Whitman, S. A.; Wu, W.; Wondrak, G. T.; Wong, P. K.; Fang, D.; Zhang, D. D. Therapeutic potential of Nrf2 activators in streptozotocin-induced diabetic nephropathy. Diabetes 60:3055-3066; 2011.

[27] Qian, Y.; Feldman, E.; Pennathur, S.; Kretzler, M.; Brosius, F. C., 3rd. From fibrosis to sclerosis: mechanisms 
of glomerulosclerosis in diabetic nephropathy. Diabetes 57:1439-1445; 2008.

[28] Stambe, C.; Atkins, R. C.; Tesch, G. H.; Masaki, T.; Schreiner, G. F.; Nikolic-Paterson, D. J. The role of p38alpha mitogen-activated protein kinase activation in renal fibrosis. J. Am. Soc. Nephrol. 15:370-379; 2004.

[29] Kang, S. W.; Adler, S. G.; Lapage, J.; Natarajan, R. p38 MAPK and MAPK kinase 3/6 mRNA and activities are increased in early diabetic glomeruli. Kidney Int. 60:543-552; 2001.

[30] Wilmer, W. A.; Dixon, C. L.; Hebert, C. Chronic exposure of human mesangial cells to high glucose environments activates the p38 MAPK pathway. Kidney Int. 60:858-871; 2001.

[31] Alexander, M. P.; Patel, T. V.; Farag, Y. M.; Florez, A.; Rennke, H. G.; Singh, A. K. Kidney pathological changes in metabolic syndrome: a cross-sectional study. Am. J. Kidney Dis. 53:751-759; 2009.

[32] Choi, S. W.; Benzie, I. F.; Ma, S. W.; Strain, J. J.; Hannigan, B. M. Acute hyperglycemia and oxidative stress: direct cause and effect? Free Radic. Biol. Med. 44:1217-1231; 2008.

[33] King, G. L.; Loeken, M. R. Hyperglycemia-induced oxidative stress in diabetic complications. Histochem. Cell Biol. 122:333-338; 2004.

[34] Ruiz-Ramirez, A.; Ortiz-Balderas, E.; Cardozo-Saldana, G.; Diaz-Diaz, E.; El-Hafidi, M. Glycine restores glutathione and protects against oxidative stress in vascular tissue from sucrose-fed rats. Clin. Sci. (London) 126:19$29 ; 2014$.

[35] Catherwood, M. A.; Powell, L. A.; Anderson, P.; McMaster, D.; Sharpe, P. C.; Trimble, E. R. Glucose-induced oxidative stress in mesangial cells. Kidney Int. 61:599-608; 2002.

[36] Solis, W. A.; Dalton, T. P.; Dieter, M. Z.; Freshwater, S.; Harrer, J. M.; He, L.; Shertzer, H. G.; Nebert, D. W. Glutamate-cysteine ligase modifier subunit: mouse Gclm gene structure and regulation by agents that cause oxidative stress. Biochem. Pharmacol. 63:1739-1754; 2002.

[37] Ghosh, J.; Das, J.; Manna, P.; Sil, P. C. Arjunolic acid, a triterpenoid saponin, prevents acetaminophen (APAP)-induced liver and hepatocyte injury via the inhibition of APAP bioactivation and JNK-mediated mitochondrial protection. Free Radic. Biol. Med. 48:535-553; 2010.

[38] Abdel-Zaher, A. O.; Abdel-Hady, R. H.; Mahmoud, M. M.; Farrag, M. M. The potential protective role of alpha-lipoic acid against acetaminophen-induced hepatic and renal damage. Toxicology 243:261-270; 2008.

[39] Xu, Z. G.; Lanting, L.; Vaziri, N. D.; Li, Z.; Sepassi, L.; Rodriguez-Iturbe, B.; Natarajan, R. Upregulation of angiotensin II type 1 receptor, inflammatory mediators, and enzymes of arachidonate metabolism in obese Zucker rat kidney: reversal by angiotensin II type 1 receptor blockade. Circulation 111:1962-1969; 2005.

[40] Jung, D. S.; Li, J. J.; Kwak, S. J.; Lee, S. H.; Park, J.; Song, Y. S.; Yoo, T. H.; Han, S. H.; Lee, J. E.; Kim, D. K.; Moon, S. J.; Kim, Y. S.; Han, D. S.; Kang, S. W. FR167653 inhibits fibronectin expression and apoptosis in diabetic glomeruli and in high-glucose-stimulated mesangial cells. Am. J. Physiol. Renal Physiol. 295:F595-604; 2008.

[41] Ren, Y.; Shi, Y.; Wang, Y.; Li, Y.; Wu, S.; Li, H.; Zhang, Y.; Duan, H. p38 MAPK pathway is involved in high glucose-induced thioredoxin interacting protein induction in mouse mesangial cells. FEBS Lett. 584:3480-3485; 2010.

[42] Sharma, K.; Jin, Y.; Guo, J.; Ziyadeh, F. N. Neutralization of TGF-beta by anti-TGF-beta antibody attenuates 
kidney hypertrophy and the enhanced extracellular matrix gene expression in STZ-induced diabetic mice. Diabetes 45:522-530; 1996.

[43] Burns, W. C.; Twigg, S. M.; Forbes, J. M.; Pete, J.; Tikellis, C.; Thallas-Bonke, V.; Thomas, M. C.; Cooper, M. E.; Kantharidis, P. Connective tissue growth factor plays an important role in advanced glycation end productinduced tubular epithelial-to-mesenchymal transition: implications for diabetic renal disease. J. Am. Soc. Nephrol. 17:2484-2494; 2006.

[44] Okada, H.; Kikuta, T.; Kobayashi, T.; Inoue, T.; Kanno, Y.; Takigawa, M.; Sugaya, T.; Kopp, J. B.; Suzuki, H. Connective tissue growth factor expressed in tubular epithelium plays a pivotal role in renal fibrogenesis. J. Am. Soc. Nephrol. 16:133-143; 2005.

[45] Gupta, S.; Clarkson, M. R.; Duggan, J.; Brady, H. R. Connective tissue growth factor: potential role in glomerulosclerosis and tubulointerstitial fibrosis. Kidney Int. 58:1389-1399; 2000.

[46] Kojima, R.; Taniguchi, H.; Tsuzuki, A.; Nakamura, K.; Sakakura, Y.; Ito, M. Hypertonicity-induced expression of monocyte chemoattractant protein-1 through a novel cis-acting element and MAPK signaling pathways. $J$.

Immunol. 184:5253-5262; 2010.

[47] Takaishi, H.; Taniguchi, T.; Takahashi, A.; Ishikawa, Y.; Yokoyama, M. High glucose accelerates MCP-1 production via p38 MAPK in vascular endothelial cells. Biochem. Biophys. Res. Commun. 305:122-128; 2003.

[48] Chow, F. Y.; Nikolic-Paterson, D. J.; Ozols, E.; Atkins, R. C.; Rollin, B. J.; Tesch, G. H. Monocyte chemoattractant protein-1 promotes the development of diabetic renal injury in streptozotocin-treated mice. Kidney Int. 69:73-80; 2006.

[49] Banba, N.; Nakamura, T.; Matsumura, M.; Kuroda, H.; Hattori, Y.; Kasai, K. Possible relationship of monocyte chemoattractant protein-1 with diabetic nephropathy. Kidney Int. 58:684-690; 2000.

[50] Yozai, K.; Shikata, K.; Sasaki, M.; Tone, A.; Ohga, S.; Usui, H.; Okada, S.; Wada, J.; Nagase, R.; Ogawa, D.; Shikata, Y.; Makino, H. Methotrexate prevents renal injury in experimental diabetic rats via anti-inflammatory actions. J. Am. Soc. Nephrol. 16:3326-3338; 2005.

Fig. 1. Acetaminophen reduces proteinuria and podocyte damage in obese Zucker rats. (A) Proteinuria was determined by the amount of urine total protein normalized to urine creatinine of the same animal. (B and C) Indices of podocyte injury were assessed by examining desmin protein levels using immunofluorescence (B, 400×; scale bar, $50 \mu \mathrm{m})$ and immunoblotting $(\mathrm{C})$. Each column represents the mean $\pm \operatorname{SEM}(n=6)$. abc, groups without the same letter are significantly different $(P \leq 0.05)$.

Fig. 2. Acetaminophen alleviates the severity of glomerulosclerosis in obese Zucker rats. (A) Representative micrographs of H\&E, PAS, and PSR staining from each experimental group (400× original magnification). (B) Semiquantitative scoring of glomerulosclerosis. Data are expressed as the mean $\pm \operatorname{SEM}(n=6)$. abc, groups without the same letter are significantly different $(P \leq 0.05)$.

Fig. 3. Acetaminophen reduces inflammatory cell infiltration and MCP-1 expression in glomeruli. (A and B) The 
number of macrophages (A) and lymphocytes (B) in the glomerulus. (C and D) Intraglomerular immunofluorescence (400×; scale bar,50 $\mu \mathrm{m})$ and renal expression of MCP-1. Each column represents the mean \pm SEM $(n=6)$. abc, groups without the same letter are significantly different $(P \leq 0.05)$.

Fig. 4. Acetaminophen decreases the expression of fibronectin, TGF- $\beta$, and CTGF in the obese Zucker kidney. (A) Fibronectin expression was measured by immunoblotting. (B and C) Intraglomerular expression of TGF- $\beta$ (B) and CTGF (C) was detected by immunofluorescence (400×; scale bar, $50 \mu \mathrm{m})$. Each column represents the mean \pm SEM $(n=6)$. ab, groups without the same letter are significantly different $(P \leq 0.05)$.

Fig. 5. Acetaminophen attenuates high-glucose-induced extracellular fibronectin deposition, profibrotic factors, and MCP-1 secretion in HRMCs. (A and B) Extracellular deposition of fibronectin (A, asterisks; 400×; scale bar, $50 \mu \mathrm{m}$ ) and the amount of soluble fibronectin secreted into the medium (B) after $48 \mathrm{~h}$ of treatment. (C-E) The secretion of TGF- $\beta$ (C), CTGF (D), and MCP-1 (E) into the medium after $48 \mathrm{~h}$ of treatment as indicated. CON, $5.5 \mathrm{mM}$ glucose; MAN, $5.5 \mathrm{mM}$ glucose + $19.5 \mathrm{mM}$ mannitol (as the osmotic control); HG, $25 \mathrm{mM}$ glucose; DMSO, $25 \mathrm{mM}$ glucose $+0.1 \%$ DMSO; APAP $3 \mu \mathrm{M}, 25 \mathrm{mM}$ glucose $+0.1 \%$ DMSO $+3 \mu \mathrm{M}$ acetaminophen; APAP $10 \mu \mathrm{M}$ (or APAP in $\mathrm{C}-\mathrm{E}), 25 \mathrm{mM}$ glucose $+0.1 \% \mathrm{DMSO}+10 \mu \mathrm{M}$ acetaminophen. Values are means $\pm \mathrm{SEM}$ of five independent experiments. abc, groups without the same letter are significantly different $(P \leq 0.05)$.

Fig. 6. Acetaminophen diminishes superoxide and 4-HNE levels in the obese Zucker glomeruli and in HRMCs cultured under high glucose. (A) Renal DHE staining. (B) Renal 4-HNE immunofluorescence. (C and D) DHE staining and 4-HNE immunofluorescence in HRMCs after $48 \mathrm{~h}$ of treatment as indicated $(n=5)$. CON, $5.5 \mathrm{mM}$ glucose; HG, $25 \mathrm{mM}$ glucose; DMSO, $25 \mathrm{mM}$ glucose + 0.1\% DMSO; APAP, $25 \mathrm{mM}$ glucose + 0.1\% DMSO + 10 $\mu \mathrm{M}$ acetaminophen. ab, groups without the same letter are significantly different $(P \leq 0.05)$. Representative images: $400 \times$; scale bar, $50 \mu \mathrm{m}$.

Fig. 7. Acetaminophen inhibits p38MAPK hyperactivation in the obese Zucker kidney and in HRMCs exposed to high glucose. (A) Renal p-p38MAPK and p38MAPK as determined by immunoblotting. Values are means \pm SEM $(n=6)$. (B) p-p38MAPK and p38MAPK in HRMCs after $48 \mathrm{~h}$ of treatment as indicated. CON, $5.5 \mathrm{mM}$ glucose; HG, $25 \mathrm{mM}$ glucose; and APAP, $25 \mathrm{mM}$ glucose $+10 \mu \mathrm{M}$ acetaminophen. Values are means \pm SEM of five independent experiments. abc, groups without the same letter are significantly different $(P \leq 0.05)$.

Fig. 8. Acetaminophen reduces $\mathrm{H}_{2} \mathrm{O}_{2}$-induced $\mathrm{p} 38$ MAPK activation and TGF- $\beta$ and MCP-1 secretion. HRMCs were exposed to $10 \mu \mathrm{M} \mathrm{H}_{2} \mathrm{O}_{2}$ for $12 \mathrm{~h}$. (A) The expression of p-p38MAPK and p38MAPK in HRMCs was determined by immunoblotting. (B and $\mathrm{C}$ ) The secretion of TGF- $\beta$ and MCP-1 into the medium was measured by ELISA. CON, control; $\mathrm{H}_{2} \mathrm{O}_{2}$, exposure to $10 \mu \mathrm{M} \mathrm{H}_{2} \mathrm{O}_{2}$; DMSO, $10 \mu \mathrm{M} \mathrm{H}_{2} \mathrm{O}_{2}+0.1 \%$ DMSO; APAP, $10 \mu \mathrm{M} \mathrm{H}_{2} \mathrm{O}_{2}+0.1 \%$ DMSO + $10 \mu \mathrm{M}$ acetaminophen. Values are means $\pm \mathrm{SEM}$ of five independent experiments. abc, groups without the same letter are significantly different $(P \leq 0.05)$. 
Fig. 9. Acetaminophen increases glutathione synthetase expression and alleviates glutathione reductase and Nrf2 expression in obese Zucker kidney. The protein expression of (A) GSH synthetase, (B) GSH reductase, and (C) Nrf2 was measured by immunoblotting. Each column represents the mean $\pm \operatorname{SEM}(n=6)$. abc, groups without the same letter are significantly different $(P \leq 0.05)$.

Fig. 10. Proposed mechanisms of metabolic syndrome-mediated glomerulosclerosis and the protective effects of acetaminophen. Prolonged metabolic abnormalities induce overproduction of ROS and oxidative stress, which activates the p38MAPK signal pathway, causing increased expression of profibrotic and proinflammatory factors and thereby leading to the pathological development of glomerulosclerosis. Acetaminophen reduces glomerular oxidative stress and inhibits p38MAPK hyperphosphorylation, which results in attenuated glomerulosclerosis. The red lines indicate the deteriorative effects of metabolic syndrome (increase/activation), and the blue lines represent protective effect of acetaminophen (decrease/inhibition). 
Fig. 1

A

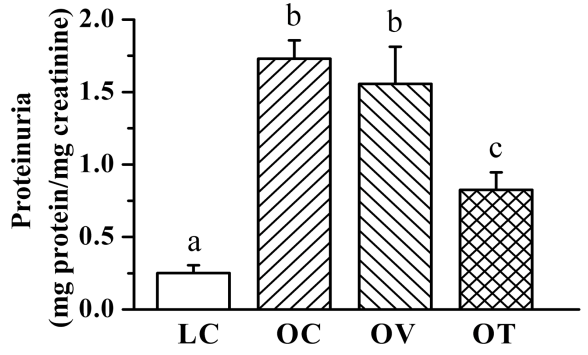

B
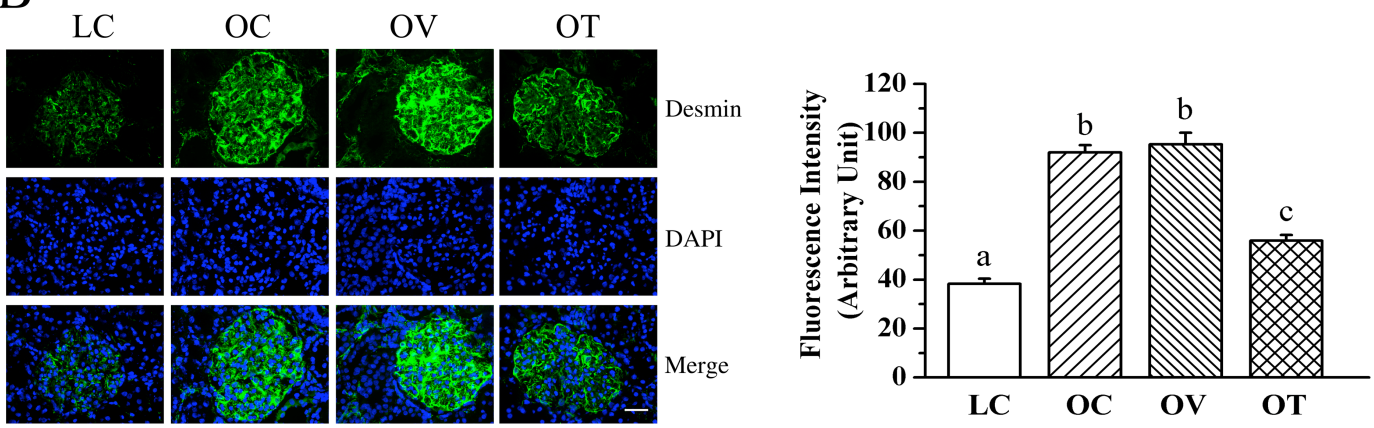

C $\quad$ LC OC OV OT

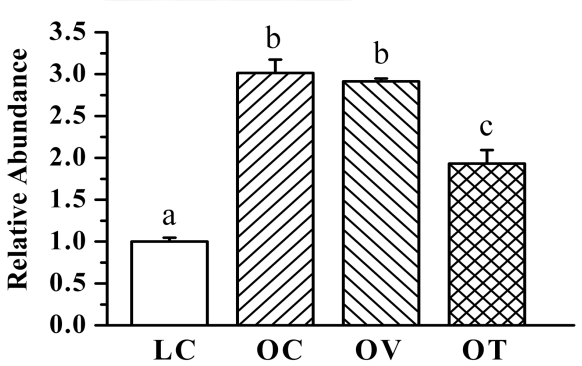


Fig. 2

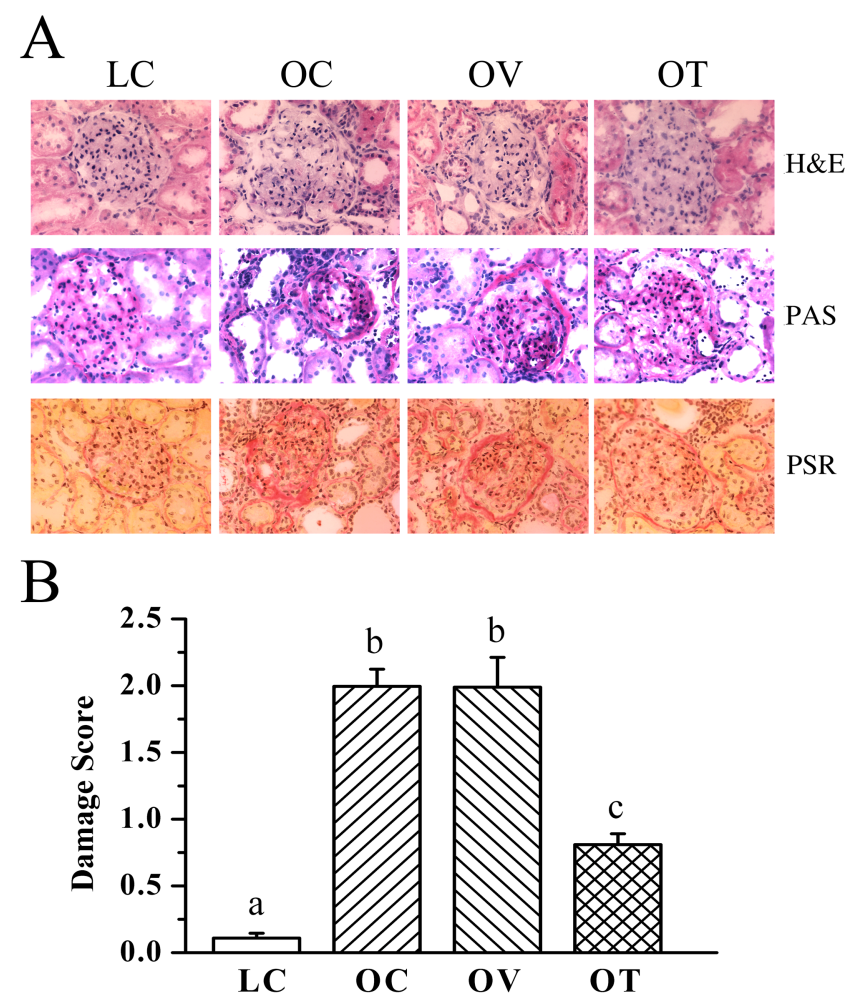


Fig. 3

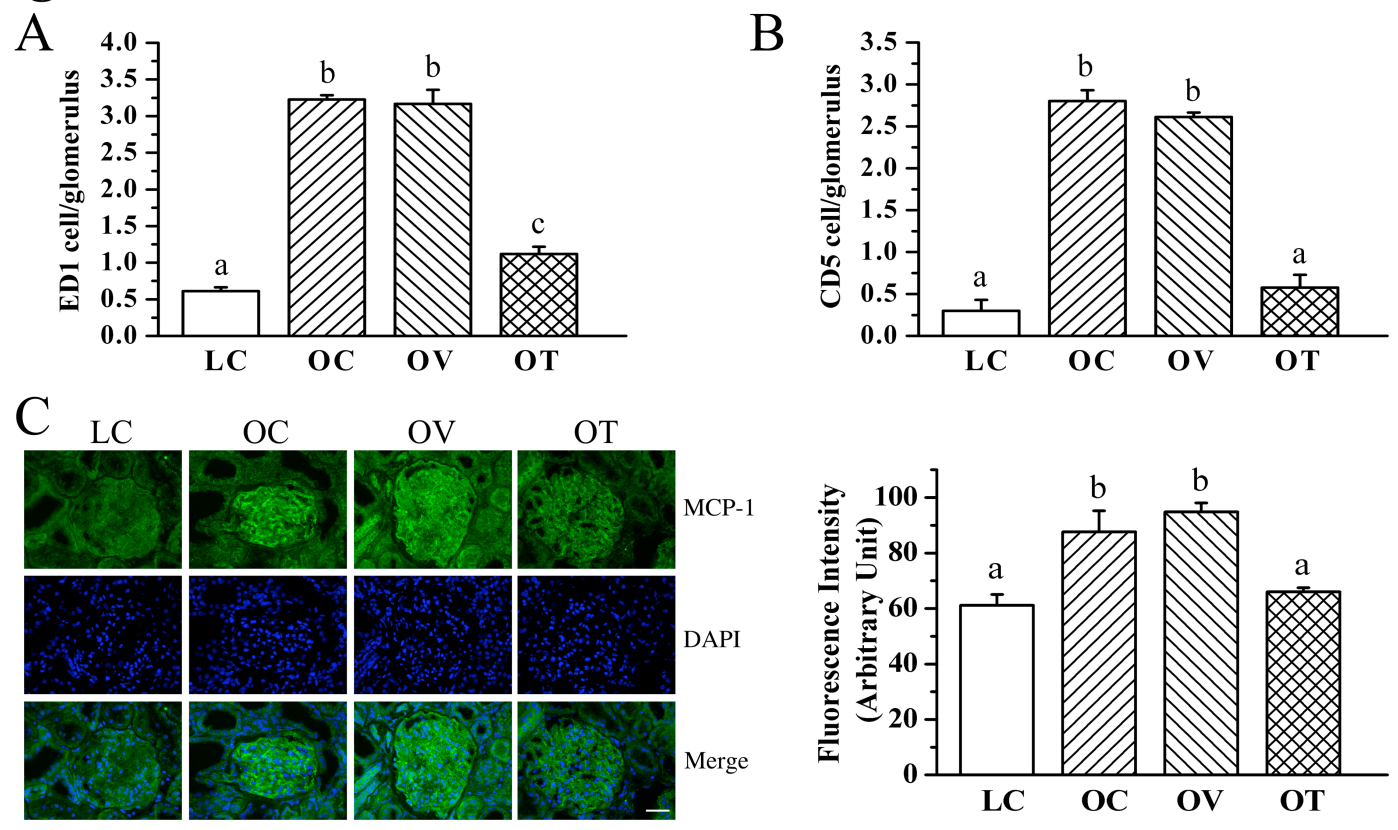

D

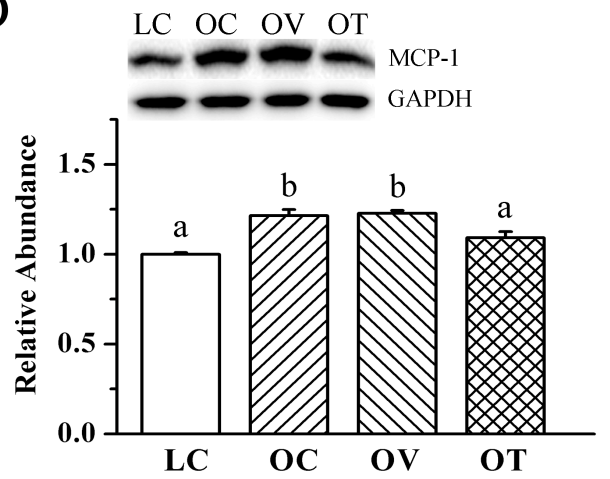


Fig. 4

A

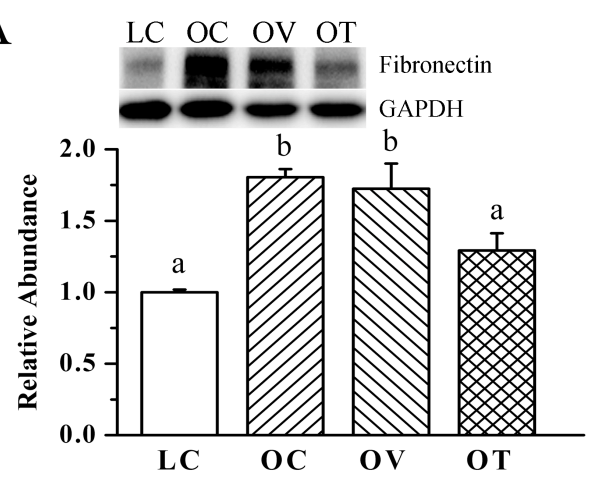

B

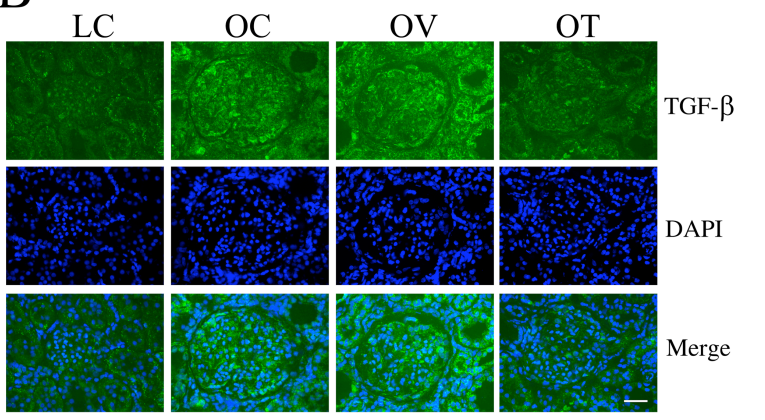

C

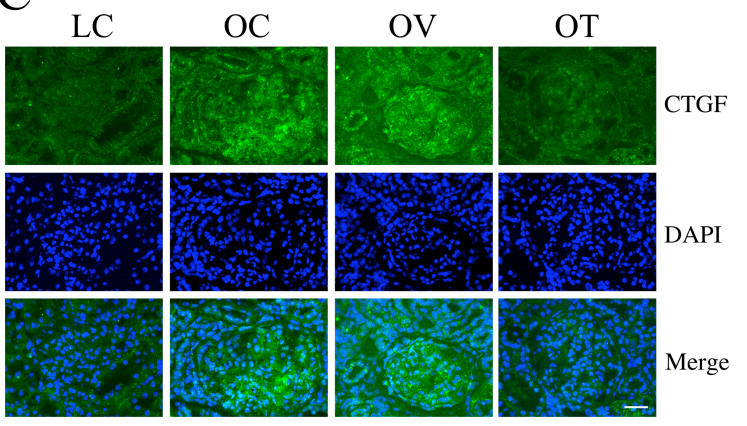

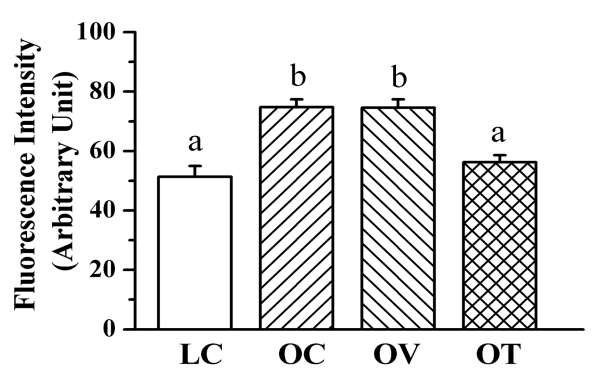

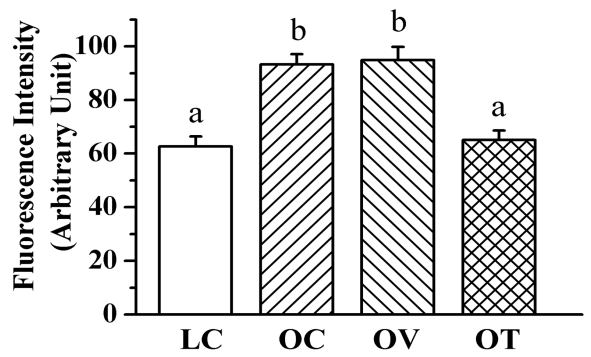


Fig. 5

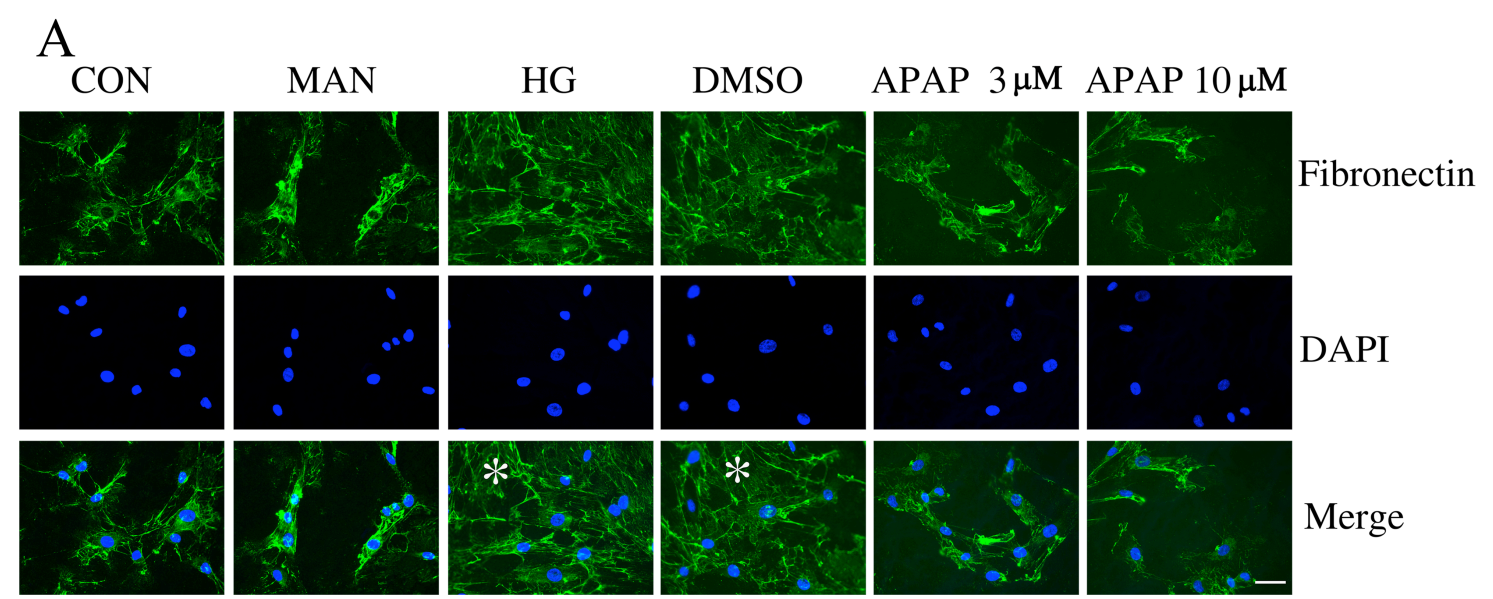

B

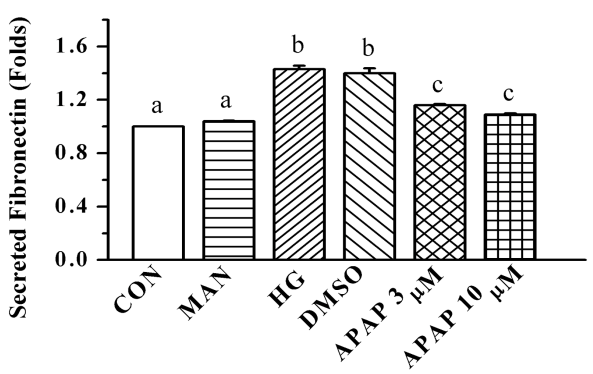

D

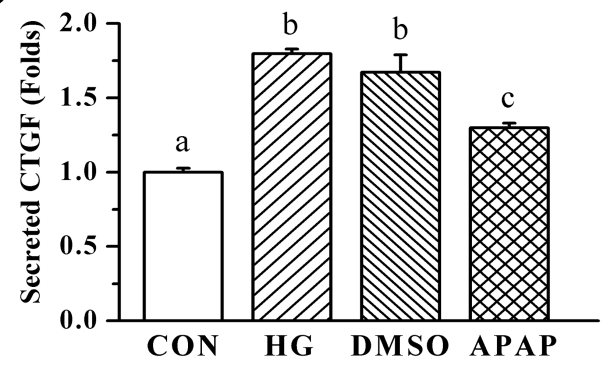

C

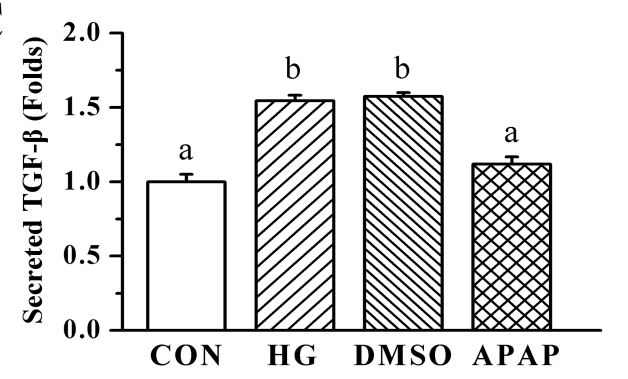

E

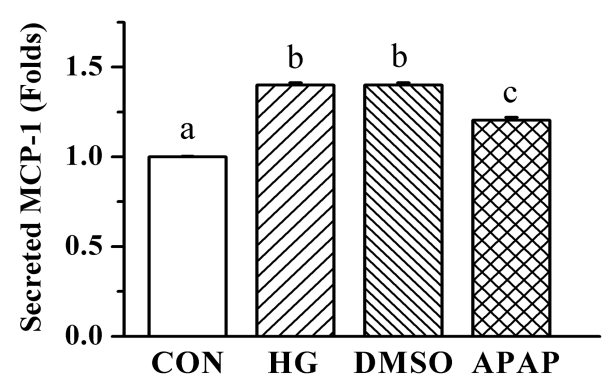


Fig. 6

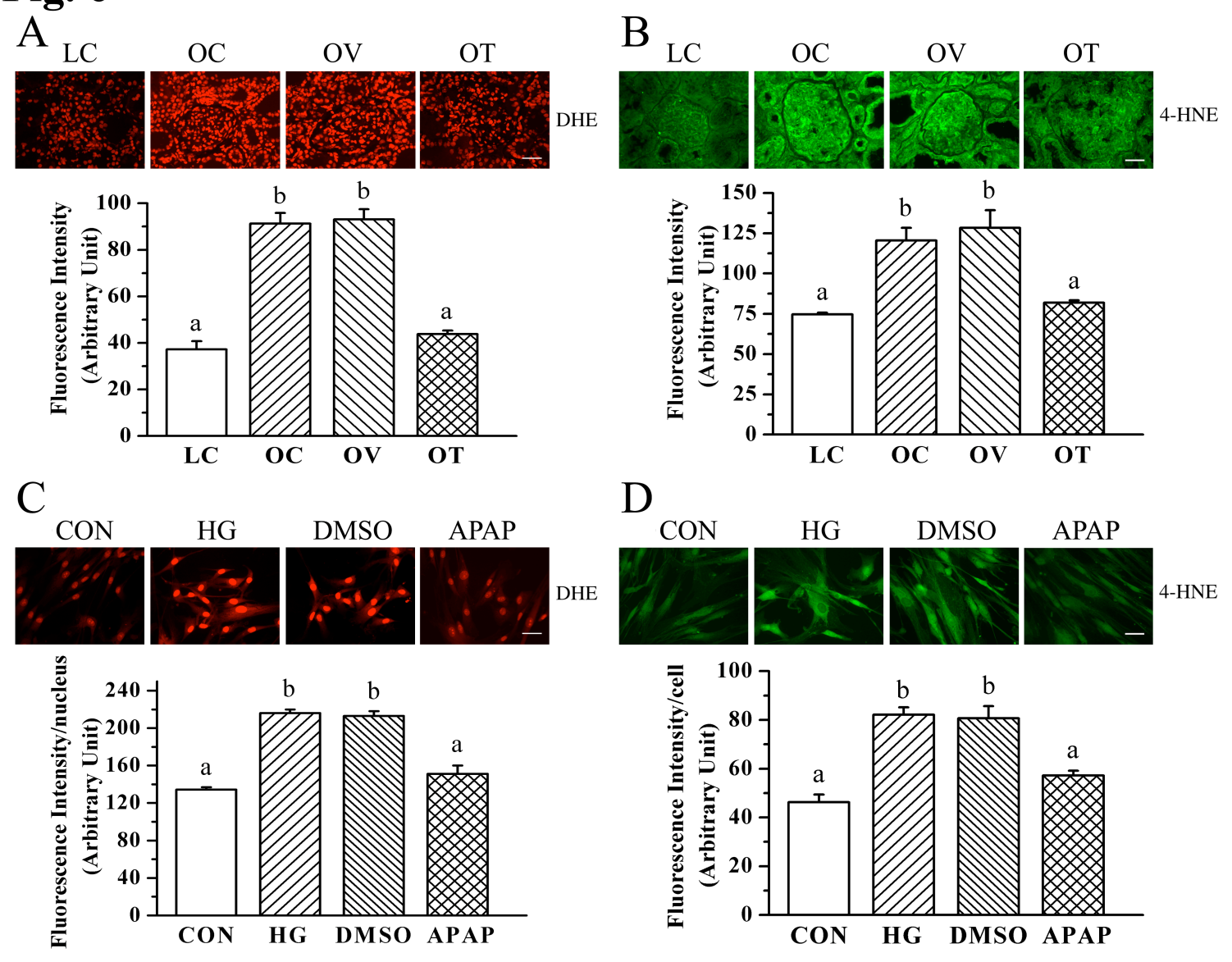


Fig. 7

A

LC OC OV OT

$=-1=0-\mathrm{p} 38 \mathrm{MAPK}$

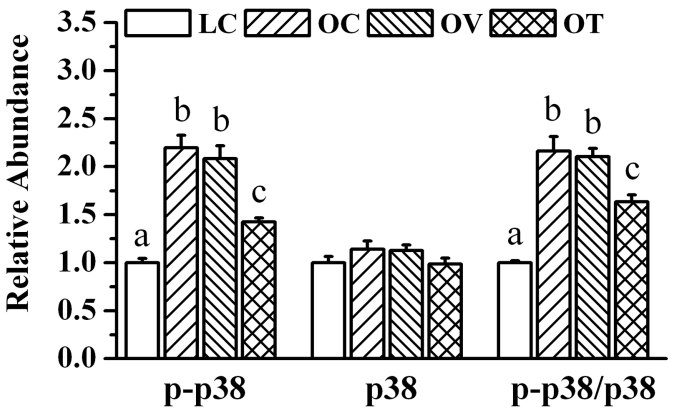

B

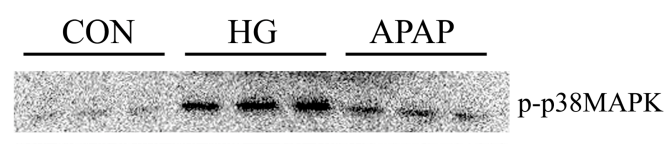

- - - - - - $\mathrm{p} 38 \mathrm{MAPK}$

-00-00-0 $\mathrm{GAPDH}$

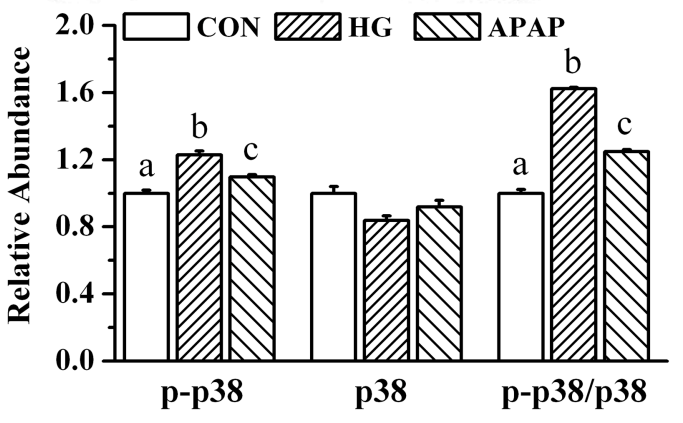




\section{Fig. 8}

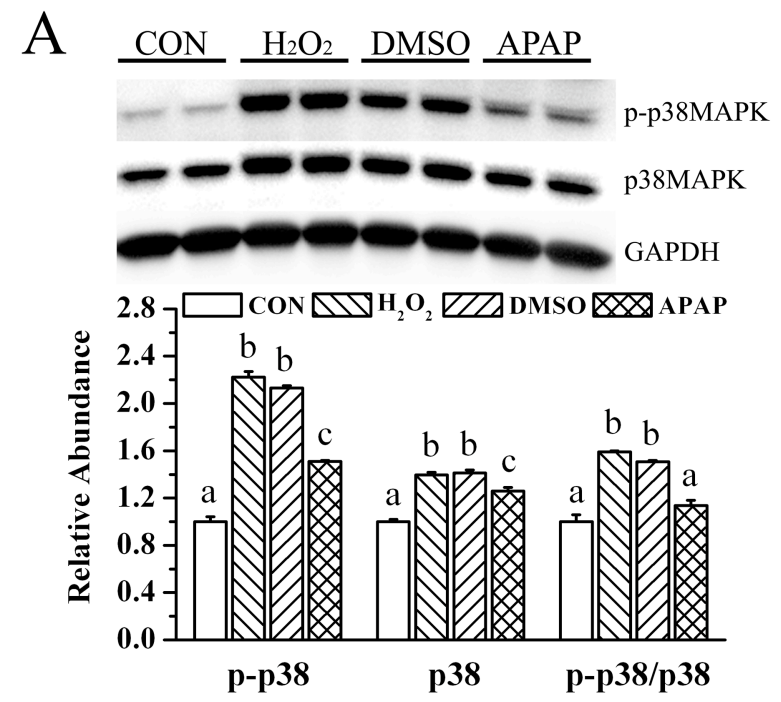

B

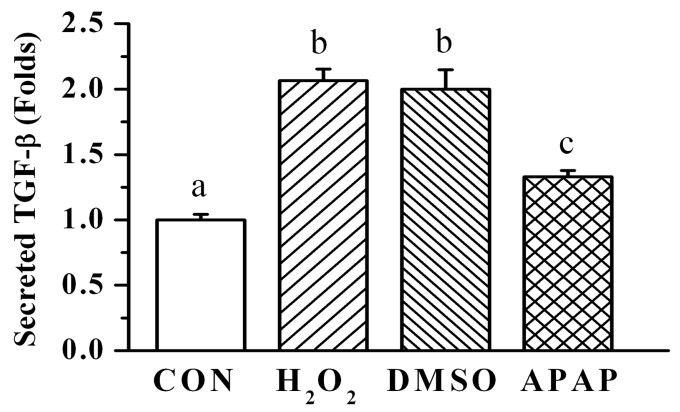

C

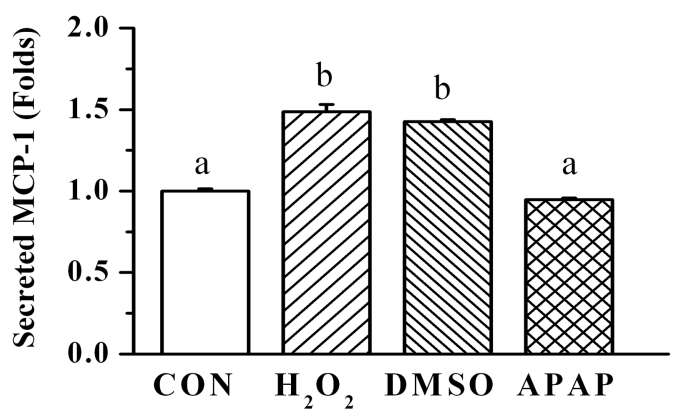




\section{Fig. 9}
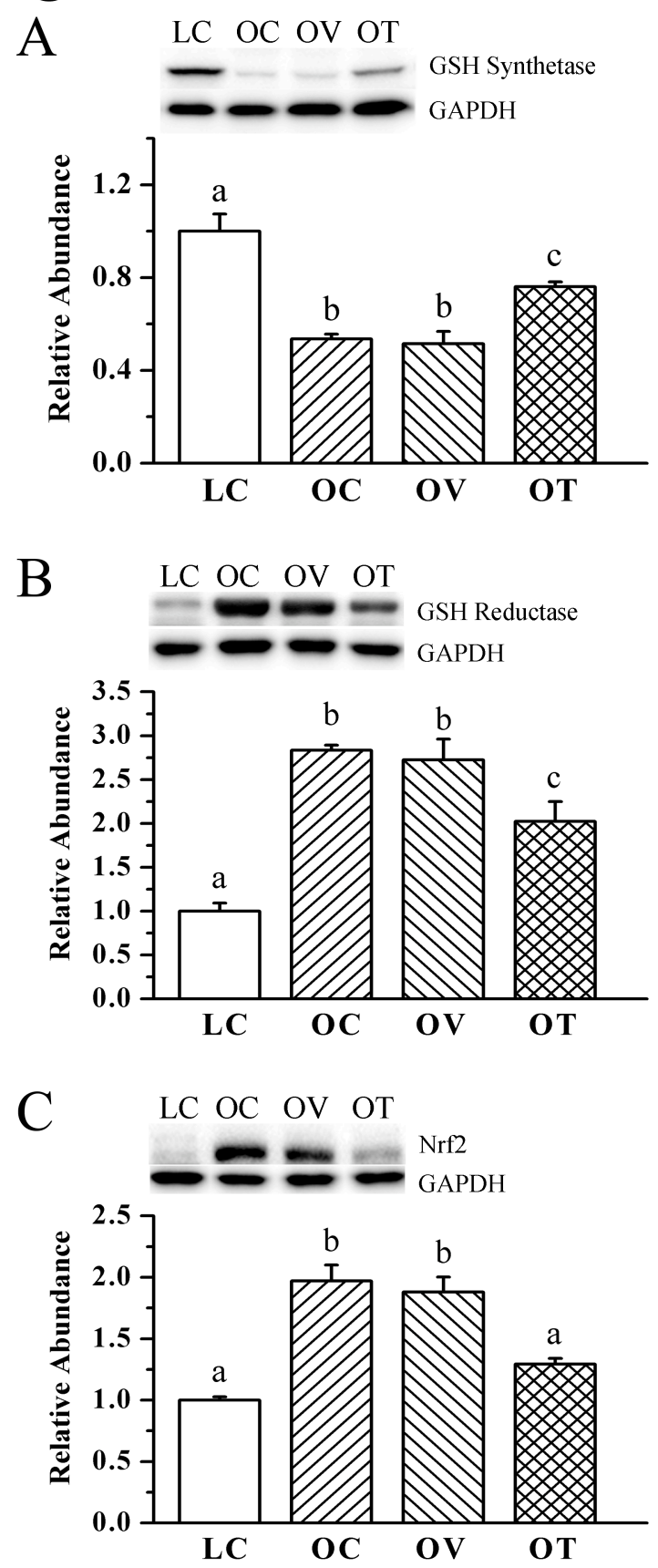


\section{Fig. 10}

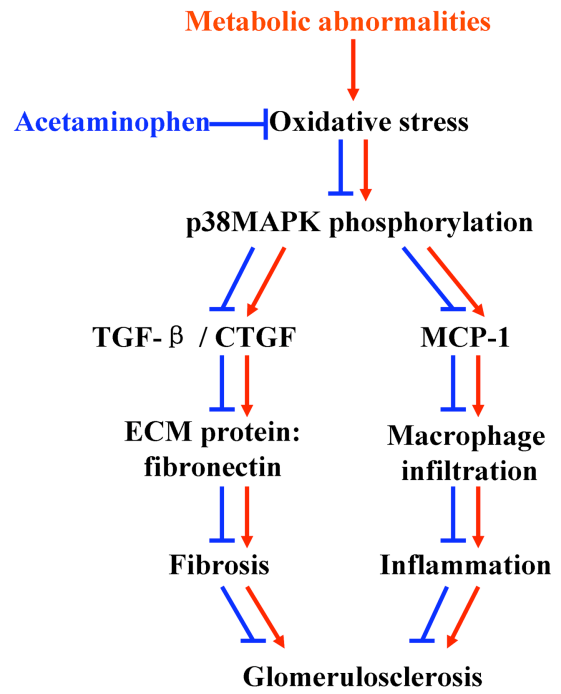

